\title{
Inside the Japanese Seed Industry: Its Characteristics and Implications for Agroecology
}

\author{
Ayako Kawai
}

\begin{abstract}
The nature of small-scale seed companies and their role in sustaining genetic diversity are understudied in developed countriesnot least Japan, which has nearly 1000 of them. In this in-depth survey, Ayako Kawai analyses findings derived from interviews with the heads of, and breeders in, three such firms. Historically, she notes, Japanese seed companies operate within close-knit networks and follow customary practices, which has helped to foster cooperation: they function as "diverse economies", collectively agreeing on seed prices and trading as equal partners. Many of them also contribute to agrobiodiversity by maintaining open pollinated varieties, and in some rare cases, by developing new non-hybrid ones. Inevitably, these practices can put them at odds with market constraints such as the demand for mainstream traits. Kawai concludes that if free-market principles were applied wholesale to Japan's seed industry, its predominantly value-led approach would suffer, with negative impacts on national crop diversity.
\end{abstract}

\section{A. Kawai $(\bowtie)$}

Research Institute for Humanity and Nature, Kyoto, Japan

Y. Nishikawa and M. Pimbert (eds.), Seeds for Diversity and Inclusion, https://doi.org/10.1007/978-3-030-89405-4_10 
Keywords Agroecology · Breeding · Customary practices · Fair Trade Commission $\cdot$ Seed companies

\subsection{INTRODUCTION}

A stable, high-quality, locally appropriate seed supply is a key element of sustainable agri-food systems. Yet recent decades have seen a massive consolidation of seed companies into huge multinational agribusinesses, sparking concern over their increasing control of the food chain as a whole, from seeds to market shelves (Howard, 2009). Over the last halfcentury, this development has transformed the sector: once composed primarily of small-scale family businesses, it now features a limited number of multinational pharmaceutical and chemical companies (FernandezCornejo \& Just, 2007; Vellve, 2009).

Without significant changes in the global political environment, the trend for consolidation is expected to continue (Howard, 2009). Such a development may further exacerbate the difficulties of instating renewable agriculture by reducing choices among farmers to obtain seeds that are locally adapted, genetically diverse, novel, non-patented and compatible with self-reproduction (Howard, 2009; Schimmelpfennig et al., 2004). In addition, the market clout of multinational pharmaceutical and chemical companies could exclude seed suppliers, who are not bound to narrow economic goals and are committed to providing diverse seeds.

Studies suggest that a number of emerging seed companies offer heirloom or open pollinated seeds in response to increasing interest among gardeners and organic farmers in the United States (Bonina \& Cantliffe, 2004; Nabhan, 2013). However, the characteristics of local small-scale seed companies and their role in maintaining and distributing genetic diversity are understudied, especially in developed countries.

This chapter explores the nature of the Japanese seed industry and describes the motivations of, and decisions made by, the heads of smallscale family-owned seed companies. It also examines their contributions to agroecology, if any. It is based on semi-structured interviews undertaken in 2016 and 2018 with the heads and breeders of three such companies. Since some of these did not want to be identified, their names, location and the type of crops they breed, are kept confidential, barring Noguchi Seed for its name. 


\subsection{CHARACTERISTICS of THE JAPANESE SEed INdUSTRY}

The global seed industry is polarized. On the one hand are largescale integrated agribusinesses; on the other, as with most Japanese seed companies, are independent operations. In Japan, such companies maintained independence from the huge multinational agribusinesses by remaining privately owned and avoiding any listing on the stock market. One of the interviewees noted that "it is Japanese culture to refuse selling their companies to foreigners even if it leads to bankruptcy". The modest size of Japanese vegetable seed markets also made them less attractive to foreign investment.

Intensified market competition and advancement in breeding technology have resulted in the rise of large seed companies and the closure of smaller ones in Japan (Hisano, 1998). Yet there are nearly 1000 seed companies registered in the country, including retailers (JSTA, 2020) - a high number compared to that in other developed nations. ${ }^{1}$ With the production and development of major crop seeds such as rice, wheat and soybean, regulated under the Main Crop Seeds Act until 2018 , most Japanese seed companies have engaged in vegetable breeding (Hisano, 1998; Matsuura, 2012). The exact number of such companies is uncertain, but it seems that nearly 40 breed Brassica varieties, for instance.

It is the Japanese seed industry's customary governance structure that seems to support the coexistence of diverse domestic vegetable breeding companies. Before seed companies were established in Japan, specialized farmers with high-level agricultural skills bred new varieties (Abe, 2015). Such producers became seed dealers in the late seventeenth century, and by the end of the nineteenth century had established the first modern seed companies (Abe, 2015). Since each company specialized in breeding one crop, they sold seeds to each other to ensure that customers enjoyed a wide range of varieties. Customary business rules, including selling seeds to each other, had been established around the late eighteenth century (Abe, 2015), and are still in place. Thus, breeding companies not only sell seeds directly to customers; they also operate as a wholesaler and sell seeds to other companies. When seeds are sold through wholesalers

${ }^{1}$ Nabhan (2013) reported that there are at least 275 vegetable seed companies in the United States and Canada. 
and retailers, customers do not know which company originally bred the variety, since its name is determined by the end sellers.

By specializing in a certain kind of crop, vegetable breeding companies have collected and developed breeds over time, which has been a distinct benefit for old, established seed companies. The head of Yamamoto, for instance, commented that having good breeding lines makes a company competitive. A breeder at Yamamoto mentioned that there are probably fewer than a dozen breeders in Japan who deal with the same crop he does. While a relatively small business, Yamamoto is competitive in terms of crops they specialize in; the world's seventh-largest seed company, Sakata in Japan, does not specialize in these crops and has become their trading partner. Large seed companies such as Sakata, which occupy much of the domestic vegetable seed market, are also large wholesalers and customers of smaller breeding companies.

Seed companies, including large ones, follow customary practices in their operations. A representative of one explained that since the Meiji era in Japan (1868-1912), major seed companies across the nation have organized regular gatherings to trade seeds through bidding, deciding sales prices, and exchanging information about market trends and the quality and amount of seed production. The Japan Fair Trade Comission regards this as cartel pricing-that is, agreed pricing by a group of producers working together to protect their interests, which restricts free-market competition.

While I did not interview anyone in detail regarding this issue, existing studies and rulings by Japan's supreme court suggest that the 32 seed companies-which provide more than $90 \%$ of domestically distributed seeds of four Brassica varieties-did engage in cartel pricing by agreeing a basic seed price at least between 1998 and 2001 (Wada, 2009). These companies were members of a specialized Japan Seed Trade Association subcommittee made up of the country's breeding and seed producing companies.

During an annual subcommittee meeting, the companies voted to determine the "standard retail price" of four crops. This became the basis for setting other standard prices, for wholesale and for selling to agricultural cooperatives, for instance. Members voted on whether to increase, decrease or keep the standard retail price from the previous year, and then decided the actual standard retail price. The companies then adjusted their seed prices using the ratio of changes in the standard retail price from the previous year. Discounts and other adjustments were sometimes made for 
individual trading partners, depending on the history of the transaction, volume of trade and transaction value (Wada, 2009). One interviewee mentioned that the annual gatherings of seed companies were slated to end later that year of 2018. It is unknown at this stage how such a change might influence this customary practice.

Links between seed companies were not limited to business relations but sometimes extended to familial relations. The head of Hakonishi explained that marriages between members of the families of seed companies were common, for instance. One of the heads interviewed noted that the industry is "close-knit" and operates like "a single family", adding: "Seed companies have a long-term relationship across two or three generations, so we are closer than relatives". He speculated that such relationships between seed companies could be unique to Japan.

The way Japanese seed companies operate, within close networks and based on customary practices, might be a factor in enabling the coexistence of various domestic companies and regulated business mergers by foreign companies.

\subsection{Small SEed Companies AND Agroecology IN JAPAN}

With the rise of breeding technology and policy reforms for mass vegetable production in Japan, vegetable breeding has shifted from developing open pollinated to hybrid varieties (Abe, 2015). Many local seed companies, facing business closures or lack of demand, no longer maintain local varieties. That could potentially lead to the loss of crop diversity.

The seed company heads interviewed noted that they face a dilemma between strictly defined market demands and their preferences to maintain old varieties or develop unique ones. The head of Yamamoto mentioned that he could no longer breed varieties with traits that he liked due to changes in market demand. Even though he valued the sweetness and soft texture of a certain crop, other market requirements need to be met, such as transportability, sturdiness and suitability for retail packaging. He noted that "it is painful that even though there are much tastier crops", the market effectively prevents companies from breeding them.

Interviewees expressed a strong desire to breed new varieties but noted that the seed companies' attitude towards pursuing uniqueness was a source of tension. Breeding new varieties was perceived as a risk in the face of conservative consumer preferences and inflexible market standards. 
Since consumers tended not to be adventurous in their choice of vegetables, the characteristics of popular crops did not change much. Breeding companies perceived it as a risk to develop varieties with new features that consumers were unfamiliar with. The head of Yamamoto confirmed the power of the market and consumer preferences-rather than farmers or seed companies - in determining the characteristics of produce. This led to seed companies, including Yamamoto, feeling that their autonomy in decisions over which varieties to maintain and develop was limited.

Despite these hurdles to maintaining and breeding niche varieties, interviewees from small seed companies developed and sold local, open pollinated and unique varieties that do not reflect mainstream market trends. Two heads mentioned farmers' needs for old varieties as the main reason to maintain them even when they do not make a profit. The head of Yamamoto explained that since "seed companies do not operate for sake of genetic resource conservation", they dropped several varieties from their catalogues every year. However, he stated that they maintained some old varieties even if the company did not profit from them, noting: "I feel that I need to provide seeds that our customers request every year". Similarly, the head of Hakonishi said that the company maintained local open pollinated varieties farmers asked for. He saw it as a duty since domestic varieties are culturally important and "it is also our task to maintain them".

Apart from the needs of farmers, and a sense of duty to preserve old varieties, personal and familial reasons also influenced seed companies' decisions to maintain local open pollinated varieties. The heads of both Hakonishi and Yamamoto maintained varieties that were developed by their fathers or grandfathers. When I asked the head of Yamamoto whether he, like traditional farmers, maintained a variety because it was handed down from their ancestors, he said yes. Some seed companies operate based on a traditional family system, similar to that of traditional farmers (see Chapter 5). Under this system, the continuation of $i e$., or the household, is the top priority. Even private companies have adopted this approach, which emphasizes to sustain the household and their businesses and prefers taking a long-term perspective rather than maximizing profit in the short term (Teranishi, 2018). Since the seed companies researched operate as family businesses, non-monetary norms and values played an important role in their decision-making. 
I found that the seed companies studied not only maintained old open pollinated varieties but also developed novel non-hybrid and minor varieties. Unusually for a seed company, Hakonishi occasionally released new open pollinated vegetable varieties developed from genetic materials that did not suit hybrid breeding. Yamamoto also actively developed unique varieties because "it is our pleasure to introduce" them. While breeding for mainstream traits was crucial, it was "not fun", so they also bred for minor or unique varieties. Yamamoto also bred a variety specifically suited to the environment and culture of the Hokkaido region. The company involved local farmers in the breeding process and sought their advice when choosing preferable lines.

Seed company interviewed also accommodated agroecological value in their business practices. Noguchi Seed sells only open pollinated seeds. Besides developing, maintaining and selling a local open pollinated turnip variety, they also sold open pollinated seeds from other companies. Given that customers can find it difficult to distinguish between hybrid and open pollinated varieties, Noguchi was popular among seed savers. The company also sold seeds online as well as in retail outlets, enabling wide distribution of varieties that are otherwise difficult to find. Its head, who emphasized the importance of seed saving for the conservation of agrobiodiversity, has also written books on how to save purchased seeds.

Breeding companies currently outsource the production of up to 95\% of seeds to other countries (Matsuura, 2012). Hakonishi, which outsources $80 \%$ of its seed production outside Japan, has decided to increase domestic seed supply by up to $50 \%$ by establishing a new seed producing company. Their decision is a response to production failures triggered by unexpected extreme weather events. While such changes would increase production costs, the head of Hakonishi noted that "it is important for farmers to secure seeds that they want, and it is our duty to provide a stable seed supply". This project is run under the government funding scheme for adding value to agricultural production and Hakonishi funded $50 \%$ of it to establish its new seed producing company.

The head of Yamamoto expressed frustration over how seed companies' public image reflects that of multinational pharmaceutical and chemical companies. He noted that such multinationals "integrate chemical products and seeds", a business model that is "definitely different from ours", adding: "People think that we are the bad guys". 


\subsection{Discussion AND ConClusion}

The commodification of seed in the global food regime has concentrated power among limited number of multinational agribusinesses. Members of the food sovereignty movement see the free trade philosophy as destructive to local economies and call for a redefinition of mechanisms for market, trade and exchange to enable producers and consumers to retrieve democratic power over food production and distribution (Nyeleni Movement for Food Sovereignty, 2007). The small-scale seed companies featured in this chapter maintained, developed and distributed niche varieties, including old local non-hybrid varieties, with an eye on values other than profits. Thus they demonstrated their potential engagement in an agroecological seed system that could benefit farmer resilience and agrobiodiversity conservation.

The members and heads of small seed companies who were interviewed maintained old varieties and developed unique varieties despite their lack of value in the official market. For those companies, seeds were not reduced to commodities but linked to family history and a sense of duty to offer high-quality seeds for the public good. Collectively, they show their commitment to communities by voluntarily producing and stocking vegetable seeds in case of catastrophe-a task previously funded by the Japanese government.

Unique customary practices among seed companies, especially mutual trading, have allowed them to provide diverse varieties to farmers. And by each specializing in different seeds, they have enabled the coexistence of many companies. Under this arrangement, companies traded their goods as equal partners regardless of their size. While further investigation is needed, customary practice to collectively decide a "standard price" might have favoured small breeding companies with limited resources. The trading system used by seed companies enhanced farmers' access to diverse types of seeds, as they could not always source local varieties within their communities (see Chapter 5). By selling seeds that can be bred from, and by not imposing patent rights on developed varieties, seed companies have not restricted farmers' access to genetic diversity.

Some heads expressed frustration over neoliberal market constraints and norms, which have eroded their autonomy in making decisions on crop characteristics. Even when seed companies are highly motivated to conserve old varieties, the lack of market demand has been demoralizing. For now, old varieties are maintained to some extent by small seed 
companies, motivated by a sense of commitment to traditional values. Yet varieties could still be disappearing, given the harshness of the business environment. As the domestic market shrinks along with a diminishing population, seed companies will need to expand their engagement with the global seed economy.

Seed companies have operated as a loosely tied social group regulating how and to what ends seeds are distributed; competition over prices has been limited. This has been regarded as problematic by the Japan Fair Trade Commission for promoting free-market capitalism. Yet another way to interpret the way seed companies operate, including through mutual agreement on seed price, is that they function as "diverse economies" (Gibson-Graham et al., 2013). By collectively deciding on seed price, they have possibly ensured solidarity among breeding companies, including small ones, and diversified options for farmers. That begs the question of how such a system could be sustainable under a strict neoliberal policy environment.

Meanwhile, it is worth noting that the Japanese seed industry was under direct government control during the Second World War; there was a merger of seed companies, and seed producers and prices were determined by the government. That has inevitably influenced the features of the informal governance structure that currently exists within the seed industry (Okada, 2005). It is also important to note the recent trend among larger seed companies to breed infertile hybrid varieties, which do not produce pollen, to prevent other companies from using them for breeding. That has sparked concerns about genetic "enclosure" within such companies.

The aim of this chapter is not to romanticize seed companies, nor to reduce concerns over the intensifying control of genetic resources among the more capital-intensive companies. However, existing studies have overlooked the other end of the spectrum, especially small, locally based companies that contribute to sustainable agri-food systems. If free-market economic principles were strictly applied to the Japanese seed industry, within which small seed companies play a crucial role, the process could dismantle the informally established governance structure. Such an intervention would damage the coexistence of diverse seed companies and the distribution of diverse varieties across the nation, which would diminish Japan's crop biodiversity. 
Acknowledgements The research has been supported partially by Research Institute for Humanity and Nature (RIHN: A constituent member of NIHU), FEAST Project (No. 14200116) and JSPS KAKENHI $17 \mathrm{H} 04627$.

\section{REFERENCES}

Abe, N. (2015). Dentōyasai wo tsukutta hitobito [People who developed traditional vegetables: A modern history of 'seed dealers']. Nōbunkyō.

Bonina, J., \& Cantliffe, D. J. (2004). Seed production and seed sources of organic vegetables. Horticultural Sciences Department, Florida Cooperative Extension Service, IFAS. University of Florida. https://doi.org/10.32473/edis-hs2272004

Fernandez-Cornejo, J., \& Just, R. E. (2007). Researchability of modern agricultural input markets and growing concentration. American Journal of Agricultural Economics, 89(5), 1269-1275. https://doi.org/10.1111/j.1467-8276. 2007.01095.x

Gibson-Graham, J. K., Cameron, J., \& Healy, S. (2013). Take back the economy: An ethical guide for transforming our communities. University of Minnesota Press.

Hisano, S. (1998). Shubyōjigyō no kōzō to kinō ni kansuru ichikōsatsu [The structure and functions of the Japanese seed system]. Review of Agricultural Economics, 54, 21-37.

Howard, P. H. (2009). Visualizing consolidation in the global seed industry: 1996-2008. Sustainability, 1, 1266-1287. https://doi.org/10.3390/sul 041266

JSTA. (2020). About the association. Retrieved February 19, 2021, from http:// www.jasta.or.jp/about/

Matsuura, M. (2012). Shushi sangyō: ninaite no henka to sijyō no kakudai [Seed industry: Changing stakeholders and market expansion]. Mitsui \& C. Global Strategic Studies Institute. Retrieved July 24, 2021, from https://www.mitsui.com/mgssi/ja/report/detail/_icsFiles/afieldfile/ 2016/10/20/120720i_matsuura.pdf

Nabhan, G. P. (Ed.). (2013). Conservation you can taste: Best practices in heritage food recovery and successes in restoring agricultural biodiversity over the last quarter century. University of Arizona Southwest Center/Slow Food USA. Retrieved July 24, 2021, from https://garynabhan.com/pbf-pdf/Conservat ionYouCanTaste.pdf

Nyeleni Movement for Food Sovereignty. (2007). Nyéléni 2007: Forum for food sovereignty. Retrieved January 6, 2022, from https://nyeleni.org/DOWNLO ADS/Nyelni_EN.pdf 
Okada, T. (2005). Senjika no nōgyō shizai mondai [The agricultural materials problem during wartime]. Agricultural History Society of Japan, 39, 11-22. https://doi.org/10.18966/joah.39.0_11

Schimmelpfennig, D., Pray, C. E., \& Brennan, M. (2004). The impact of seed industry concentration on innovation: A study of US biotech market leaders. Agricultural Economics, 30(2), 157-167. https://doi.org/10.1111/j.15740862.2004.tb00184.x

Teranishi, J. (2018). Nihongata shihon shugi [Japanese style capitalism]. ChūōKōron shinsha.

Vellve, R. (2009). Saving the seed: Genetic diversity and European agriculture. Earthscan.

Wada, T. (2009). Shushi kakaku karuteru shinketsu torikeshi soshō jiken hanketsu no kentō [Evaluating the judgment in the case of the revocation of the trial decision on the seed price cartel]. NBL Antitrust Law Case Study Group, 914, 63-70.

Open Access This chapter is licensed under the terms of the Creative Commons Attribution 4.0 International License (http://creativecommons.org/licenses/ by $/ 4.0 /$ ), which permits use, sharing, adaptation, distribution and reproduction in any medium or format, as long as you give appropriate credit to the original author(s) and the source, provide a link to the Creative Commons license and indicate if changes were made.

The images or other third party material in this chapter are included in the chapter's Creative Commons license, unless indicated otherwise in a credit line to the material. If material is not included in the chapter's Creative Commons license and your intended use is not permitted by statutory regulation or exceeds the permitted use, you will need to obtain permission directly from the copyright holder.

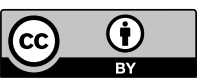

